\title{
Post-Transcriptional Regulation of RseA by Small RNAs RyhB and FnrS in Escherichia coli
}

\section{OPEN ACCESS}

Edited by:

Olga N. Ozoline,

Institute of Cell Biophysics (RAS),

Russia

Reviewed by:

Satish Raina,

Gdansk University of Technology,

Poland

Tracy Raivio,

University of Alberta, Canada

Andrey Shadrin,

Institute of Biochemistry and

Physiology of Microorganisms (RAS),

Russia

*Correspondence:

Karl M Thompson

karl.thompson@howard.edu

Specialty section:

This article was submitted to Protein and RNA Networks,

a section of the journal

Frontiers in Molecular Biosciences

Received: 16 February 2021 Accepted: 03 September 2021 Published: 03 November 2021

Citation:

London LY, Aubee Jl, Nurse J and Thompson KM (2021) PostTranscriptional Regulation of RseA by

Small RNAs RyhB and FnrS in

Escherichia coli.

Front. Mol. Biosci. 8:668613.

doi: $10.3389 /$ fmolb.2021.668613

\author{
Laricca Y. London ${ }^{1}$, Joseph I Aubee ${ }^{2}$, Jalisa Nurse ${ }^{2,3}$ and Karl M Thompson ${ }^{2 *}$ \\ ${ }^{1}$ Department of Biological and Environmental Sciences, Alabama A\&M University, Huntsville, AL, United States, ${ }^{2}$ Department of \\ Microbiology, College of Medicine, Howard University, Washington, DC, United States, ${ }^{3}$ Department of Biology, Howard \\ University, Washington, DC, United States
}

RseA is the critical central regulator of the $\sigma^{\mathrm{E}}$-dependent stress response in $E$. coli and other related bacteria. The synthesis of RseA is controlled at the transcriptional level by several promoters and transcriptional regulators, including $\sigma^{\mathrm{E}}$ itself at two $\sigma^{\mathrm{E}}$-dependent promoters: $r p o E_{\mathrm{P}}$ and $r s e A_{\mathrm{P}}$. The presence of these two independent polycistrons encoding $r s e A$ is potentially redundant. We hypothesized that post-transcriptional control of the $r s e A_{\mathrm{P} 3}$ transcript was necessary to overcome this redundancy. However, to date, nothing is known about the post-transcriptional control of the $r s e A_{\mathrm{P} 3}$ transcript. We executed a targeted genetic screen to identify small RNA regulators of the rse $A_{\mathrm{P} 3}$ transcript and identified RyhB and FnrS as small RNA activators of the RseA P3 transcript. Through genetic analysis, we confirmed that a direct interaction occurs between RyhB and RseA. We also identified sequences within the $5^{\prime}$ untranslated region (UTR) of RseA that were inhibitory for RseA expression. Point mutations predicted to prevent an interaction between RyhB and RseA resulted in increased RseA expression. Taken together, this suggests that the 5' UTR of the RseAP3 transcript prevents optimal expression of RseA, preventing redundancy due to RseA expression from the $\sigma^{\mathrm{E}}$-dependent $r p o E_{\mathrm{p}}$, and this is overcome by the stimulatory activity of RyhB and FnrS.

Keywords: small RNA, RyhB, FnrS, Escherichia coli, envelope stress response

\section{INTRODUCTION}

The cell envelope promotes structural integrity of bacteria under dynamic conditions. The cell envelope can be perturbed via internal or external cues. Envelope stress occurs as a result of excess or mis-folded outer membrane proteins (OMPs), subsequently resulting in the activation of the extracytoplasmic function (ECF) sigma factor, $\sigma^{\mathrm{E}}$ (Erickson et al., 1987; Mecsas et al., 1993; Walsh et al., 2003). Over-expression or mis-folding of OMPs can compromise the integrity of the bacterial cell envelope and therefore bacterial cell survival (Walsh et al., 2003).

E. coli and other bacterial species have developed an envelope stress response (ESR) that restores homeostasis following the onset of envelope stress. The ESR can be mediated by several key regulators in E. coli, most notably CpxR and $\sigma^{\mathrm{E}}$ (Ravio, 1999; Ravio et al., 1999). In this work, we focused on the $\sigma^{\mathrm{E}}$-dependent ESR. Activation of $\sigma^{\mathrm{E}}$-dependent promoters results in the transcriptional initiation of at least 60 genes, many of which encode proteins necessary for the resolution of the ESR (Dartigalongue et al., 2001; Johansen et al., 2006; Rhodius et al., 2006; Thompson et al., 2007). Effectors of the ESR include small RNAs and periplasmic proteases that act to repress OMP levels (Douchin et al., 2006; Johansen et al., 2006; Rhodius et al., 2006; Thompson et al., 2007; Vogt et al., 2014). The stabilization of OMP levels 

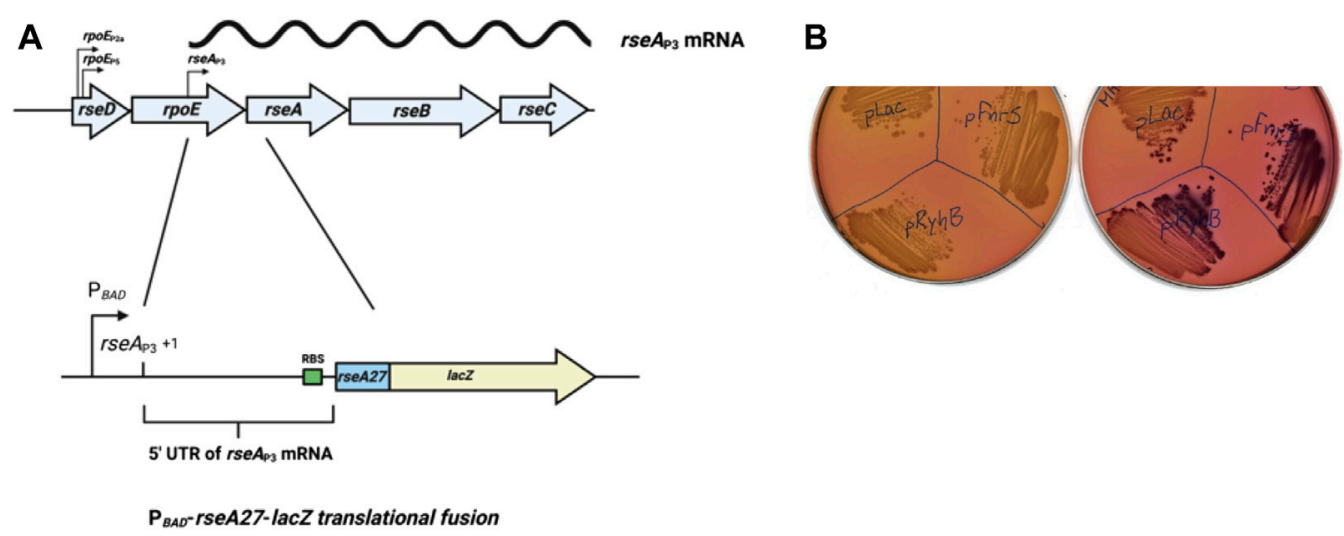

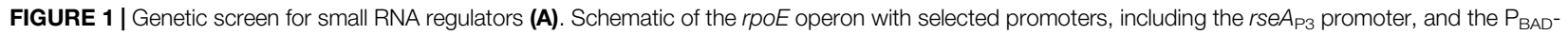
rseA27-lacZ translational fusion utilized for the small RNA library screen. The rseA fusion consists of the rseA P3 transcript, and the first nine codons of the rseA gene fused in the frame to the ninth codon of lac $Z$, downstream and controlled by the araBAD promoter ( $P_{B A D}-r s e A 27-l a c Z$ translational fusion) (B). $P_{B A D}-r s e A 27-l a c Z$ translational fusion strains transformed with an empty vector control (pBR-pLac), pBR-ryhB, or pBR-fnrS grown overnight at $37^{\circ} \mathrm{C}$ on $\mathrm{MacConkey-Lactose}$ agar plates. One plate was supplemented with $0.0002 \%$ arabinose to stimulate basal transcription of the $P_{B A D}-r s e A 27-l a c Z$ translational fusion.

restores cell envelope homeostasis. This also results in decreased $\sigma^{\mathrm{E}}$ activity. It is critically important to ensure that the steady-state levels of $\sigma^{\mathrm{E}}$ do not increase indefinitely as $\sigma^{\mathrm{E}}$ over-expression results in cell lysis and death (Nitta et al., 2000; Kabir et al., 2005). The small RNAs that act as $\sigma^{\mathrm{E}}$-dependent ESR effectors include MicA, RybB, and MicL; all of which have $\sigma^{\mathrm{E}}$-dependent promoters, repress expression of outer membrane proteins, and regulate LPS composition (Johansen et al., 2006; Thompson et al., 2007; Udekwu and Wagner, 2007; Klein et al., 2011; Klein and Raina, 2017).

The $\sigma^{\mathrm{E}}$-dependent ESR is tightly controlled via regulation of the $r p o E$ operon ( $r s e D$-rpoE-rseA-rseB-rseC) at transcriptional and post-transcriptional levels (Klein et al., 2016; Yakhnin et al., 2017). There are several promoters driving expression of this operon in concert with multiple transcription and sigma factors (Klein et al., 2016; Klein and Raina, 2017; Yakhnin et al., 2017). Transcriptional control of the $\sigma^{\mathrm{E}}$-dependent promoters is also controlled by guanosine $3^{\prime}, 5^{\prime}$-bispyrophosphate (ppGpp) and promoter architecture (Costanzo and Ades, 2006; Thompson et al., 2007; Costanzo et al., 2008; Balbontin et al., 2010). Only two of the promoters driving expression of the $r p o E$ operon are $\sigma^{\mathrm{E}}$-dependent, while the others are cognate partners to $\sigma^{54}, \sigma^{\mathrm{s}}, \sigma^{70}$, or other transcriptional regulators (Klein et al., 2016). All promoters driving expression of the $r p o E$ operon are localized upstream of, or within, the $r p o E$ leader peptide (RseD) (Figure 1A). The remaining $\sigma^{\mathrm{E}}$-dependent promoter $\left(r s e A_{\mathrm{P} 3}\right)$ is located within the $r p o E$ coding region, over 230 nucleotides upstream of the rseA start codon (Rhodius et al., 2006). The $\sigma^{\mathrm{E}}$-dependent $r s e A_{\mathrm{P} 3}$ promoter drives the synthesis of an $r s e A$ rse B-rseC transcript, while the $\sigma^{\mathrm{E}}$-dependent promoter $r p o E_{\mathrm{P}}$ drives the synthesis of the entire rseD-rpoE-rseA-rseB-rseC transcript (Rhodius et al., 2006). The activity of the $\sigma^{\mathrm{E}}$-dependent stress response is also regulated at the transcriptional level by the activity of RseA.

RseA is the anti-sigma factor for $\sigma^{\mathrm{E}}$ and plays a central role in envelope stress signal transduction (De Las Penans et al., 1997; Missiakas et al., 1997; Ades et al., 1999). RseA spans the inner membrane of the cell envelope and utilizes its cytoplasmic domain to interact with $\sigma^{\mathrm{E}}$ (Campbell et al., 2003). RseA sequesters $\sigma^{\mathrm{E}}$ to the inner member under vegetative growth conditions and thereby prevents access of $\sigma^{\mathrm{E}}$ to its cognate promoters (Campbell et al., 2003). Envelope stress stimulates a signal transduction cascade culminating in regulated intramembrane proteolysis (RIP) of RseA by periplasmic proteases DegS and RseP (De Las Penans et al., 1997; Missiakas et al., 1997; Alba et al., 2002; Kanehara et al., 2002). Following this, the N-terminus of RseA enters the cytoplasm in complex with $\sigma^{\mathrm{E}}$, whereby the RseA N-terminus is then cleaved by the adenosine $5^{\prime}$-triphosphate-dependent protease ClpXP (Flynn et al., 2004).

The synthesis of RseA from $\sigma^{\mathrm{E}}$-dependent $r s e A_{\mathrm{P} 3}$ and $r p o E_{\mathrm{P}}$ promoters has the potential to be physiologically redundant. It is likely that post-transcriptional regulation of $r p o E$ and $r s e A B C$ operons removes any physiological redundancy. While posttranscriptional regulatory mechanisms have been identified for the $r p o E$ operon, little is known about post-transcriptional regulation of the rse $A B C$ operon. The $r s e A B C$ operon has a 228 nucleotide $5^{\prime}$ untranslated region (UTR) (Rhodius et al., 2006). Due to the presence of the relatively long $5^{\prime}$ UTR for the $r s e A B C$ operon, we hypothesized that cis-acting RNA structures and trans-acting small RNAs regulate the expression of rseABC operon. To test this hypothesis, we constructed an arabinoseinducible rseA-lac $Z$ translational fusion and screened it with a small RNA library. We identified RyhB and FnrS as factors that stimulate post-transcriptional expression of RseA.

\section{MATERIALS AND METHODS}

\section{Media and Growth Conditions}

All strains were grown in Luria Bertani (Lennox) liquid media (LB) at $37^{\circ} \mathrm{C}$, with the exception of $\lambda$-Red-based recombineering strains using mini- $\lambda$ :tet lysogens. These strains were grown in LB at 
TABLE 1 | Strain list.

\begin{tabular}{|c|c|}
\hline Strain & Genotype \\
\hline KMT1 & Escherichia coli MG1655 \\
\hline KMT432 & 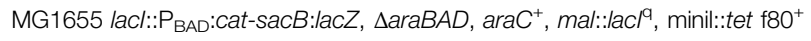 \\
\hline KMT465 & MG1655 $\Delta r y h B:: z e o$ \\
\hline KMT467 & MG1655 lac/ ${ }^{a} \Delta$ fnrS::kan \\
\hline KMT519 & NM525 pBR-pLac-fnrS-I \\
\hline KMT520 & NM525 pBR-pLac-fnrS-\|I \\
\hline KMT521 & NM525 pBR-pLac-fnrS-III \\
\hline KMT590 & MG1655 lacl::P $\mathrm{BAD}_{\mathrm{BA}}: c a t-s a c B: l a c Z, \triangle a r a B A D$, araC+, mal::lac/ ${ }^{q}$, minil::tet $\phi 80$ \\
\hline
\end{tabular}

KMT20005 MG1655

KMT20060 MG1655 $\triangle a r a B A D$, araC $^{+}$, mal::lacl ${ }^{9}$ lacl::P $P_{B A D}-r s e A 27-l a c Z$ translational fusion $\Delta r y h B:: z e o$

KMT20082 MG1655 $\triangle a r a B A D, a r a C^{+}$, mal::lacl ${ }^{a}$ lacl::P $P_{B A D}-r s e A 27-l a c Z$ translational fusion (2) $\Delta r y h B:: z e o \Delta f h r S:$ kan

KMT20088 MG1655 $\triangle a r a B A D$, araC $^{+}$, mal::lacla lacl:: $P_{B A D}-r s e A 27-l a c Z$ translational fusion $\Delta r y h B:: z e o \Delta f n r S:: k a n$ pBR-pLac

KMT20089 MG1655 $\triangle a r a B A D, a r a C^{+}$, mal::lacla lacl::P $P_{B A D}-r s e A 27-l a c Z$ translational fusion $\Delta r y h B:: z e o \quad \Delta$ fnrS::kan pBR-pLac-fnrS

KMT20090 MG1655 $\triangle a r a B A D$, araC $^{+}$, mal::lacl ${ }^{\mathrm{a}}$ lacl::P $\mathrm{P}_{B A D^{-}}$rseA27-lacZ translational fusion $\Delta r y h B:: z e o \quad \Delta f n r S:: k a n$ pBR-pLac-ryhB

KMT20109 MG1655 $\triangle a r a B A D$, araC $^{+}$, mal::lacl ${ }^{q}$ lacl:: $P_{B A D}-r s e A 27-l a c Z$ translational fusion $\Delta r y h B:: z e o$ fnrS::kan pBR-pLac-ryhBm1

KMT20110 MG1655 $\triangle a r a B A D, a r a C^{+}$, mal::lacl ${ }^{q}$ lacl::P BAD $^{-r s e A 27-l a c Z ~ t r a n s l a t i o n a l ~ f u s i o n ~}$ $\Delta r y h B:: z e o \quad \Delta f n r S:: k a n$ pBR-pLac-ryhBm2

KMT20111 MG1655 $\triangle a r a B A D, a r a C^{+}$, mal::lacl ${ }^{q}$ lacl::P $P_{B A D}-r s e A 27-l a c Z$ translational fusion $\Delta r y h B:: z e o \Delta f n r S:: k a n$ pBR-pLac-ryhBm3

KMT20112 MG1655 $\triangle a r a B A D, a^{2} C^{+}$, mal::lacl ${ }^{\natural}$ lacl::P $P_{B A D}-r s e A 27-l a c Z$ translational fusion $\Delta r y h B:: z e o \quad \Delta f n r S:: k a n$ pBR-pLac-ryhBm4

KMT20113 MG1655 $\triangle a r a B A D, a^{2} C^{+}$, mal::lacla lacl:: $P_{B A D}-r s e A 27-l a c Z$ translational fusion $\Delta r y h B:: z e o \quad \Delta f n r S:: k a n$ pBR-pLac-fnrS-I

KMT20114 MG1655 $\triangle a r a B A D, a^{2} C^{+}$, mal::lacl ${ }^{\natural}$ lacl::: $P_{B A D}-r s e A 27-l a c Z$ translational fusion $\Delta r y h B:: z e o \quad \Delta f n r S:: k a n$ pBR-pLac-fnrS-ll

KMT20115 MG1655 $\triangle$ araBAD, araC ${ }^{+}$, mal::lacl ${ }^{q}$ lacl:: $P_{B A D}-r s e A 27-l a c Z$ translational fusion $\Delta r y h B:: z e o \Delta f n r S:: k a n$ pBR-pLac-fnrS-III

KMT20144 MG1655 $\triangle a r a B A D$, araC $^{+}$, mal::lacl ${ }^{a}$ lacl::P $P_{B A D}-r s e A 27-l a c Z$ translational fusion

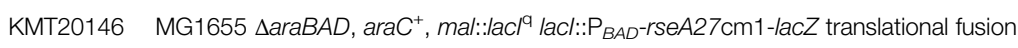

KMT20148 MG1655 $\triangle a r a B A D$, araC $^{+}$, mal::lacl $^{a}$ lacl::P $\mathrm{BAD}^{-} \mathrm{rse} A 27 \mathrm{~cm} 3-\mathrm{lac} Z$ translational fusion

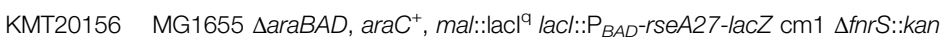

KMT20160 MG1655 $\triangle a r a B A D$, araC $^{+}$, mal::lacl ${ }^{a}$ lacl::P $P_{B A D}-r s e A 27-l a c Z$ cm3 $\Delta$ fnrS::kan

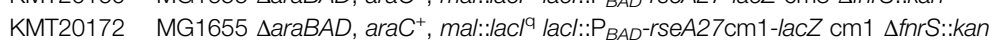
$\Delta r y h B:: z e o$

KMT20174 MG1655 $\triangle$ araBAD, araC ${ }^{+}$, mal::lacla lacl::P ${ }_{B A D}-r s e A 27-l a c Z$ cm3 $\Delta$ fnrS::kan $\Delta r y h B:: z e o$

KMT20178 MG1655 $\Delta a r a B A D$, araC ${ }^{+}$, mal::lacl ${ }^{q}$ lacl::P(PAD-rseA27cm1-lacZ $\Delta$ fnrS::kan $\Delta r y h B::$ zeo pBR-pLac

KMT20179 MG1655 $\Delta a r a B A D$, araC $^{+}$, mal::lacl ${ }^{q}$ lacl::P $P_{B A D^{-}}$rseA27cm1-lacZ $\Delta$ fnrS::kan $\Delta r y h B::$ zeo pBR-pLac-ryhB

KMT20180 MG1655 $\triangle a r a B A D, a r a C^{+}$, mal::lacl`a lacl::P ${ }_{B A D}-r s e A 27 c m 1-l a c Z \Delta f n r S:: k a n \Delta r y h B:$ zeo pBR-pLac-ryhBm1

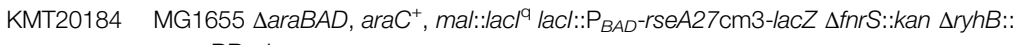
zeo pBR-pLac

KMT20185 MG1655 $\Delta a r a B A D, a r a C^{+}$, mal::lacl ${ }^{q}$ lacl::P $P_{B A D}-r s e A 27 c m 3-l a c Z ~ \Delta f n r S:: k a n \Delta r y h B::$ zeo pBR-pLac-ryhB

KMT20186 MG1655 $\triangle a r a B A D, a r a C^{+}$, mal::lacl ${ }^{a}$ lacl::P $P_{B A D}-r s e A 27 c m 3-l a c Z \Delta f n r S:: k a n \Delta r y h B::$ zeo pBR-pLac-ryhB-m3

KMT20196 MG1655 $\triangle$ araBAD, araC $^{+}$, mal::lac/ /acl::P BAD $^{-r s e A-3 X F L A G ~ w . t . ~ \# 1 ~}$

KMT20234 MG1655 $\triangle a r a B A D, a r a C^{+}$, mal::lacl $^{a}$ lacl::PBAD $-r s e A-3 X F L A G$ w.t. \#1 $\Delta r y h B:: z e o$

\section{Source}

Pierre Mandin, Ph.D. (PM1205); Mandin and Gottesman (2009)

Nicolas DeLay, Ph.D

Gisela Storz, Ph.D.; Durand and Storz (2010)

Giselia Storz, Ph.D.; Durand and Storz (2010)

Giselia Storz, Ph.D.; Durand and Storz (2010)

Giselia Storz, Ph.D.; Durand and Storz (2010)

Nadim Majdalani - PM1805

This work, KMT432 x $P_{B A D}$ rseA27-lacZ PCR $42^{\circ} \mathrm{C}$ induction and selection on M63-Glycerol-XG

This work, KMT20005 x P1 (KMT465 - sryhB::zeo source)

This work, KMT20060 x P1 (KMT467 - sfnrS::kan source)

This work, KMT20082 + pBR-pLac (TSS Transformation)

This work, KMT20082 + pBR-pLac-fnrS (TSS Transformation)

This work, KMT20082 + pBR-pLac-ryhB (TSS Transformation)

This work, KMT20082 + pBR-pLac-ryhBm1 (TSS Transformation)

This work, KMT20082 + pBR-pLac-ryhBm2 (TSS Transformation)

This work, KMT20082 + pBR-pLac-ryhBm3 (TSS Transformation)

This work, KMT20082 + pBR-pLac-ryhBm4 (TSS Transformation)

This work, KMT20082 + pBR-pLac-fnrS-I (TSS Transformation)

This work, KMT20082 + pBR-pLac-fnrS-II (TSS Transformation)

This work, KMT20082 + pBR-pLac-fnrS-III (TSS Transformation)

This work, KMT590 $\times \mathrm{P}_{B A D}$-rseA27-lacZ gBlock amplified with KT902 + KT1137

This work, KMT590 x $\mathrm{P}_{B A D}-$ rseA27cm1-lacZ gBlock amplified with KT902 + KT1137

This work, KMT590 x $\mathrm{P}_{B A D}-\mathrm{rse}$ 27 $7 \mathrm{~cm} 3-\mathrm{lac} Z$ gBlock amplified with KT902 + KT1137

KMT20146 x P1 ( $\Delta$ fnrS::kan)

This work, KMT20148 x P1 ( $\Delta$ fnrS::kan)

This work, KMT20156 x P1 (sryhB::zeo)

This work, KMT20160 x P1 (sryhB::zeo)

This work, KMT20172 + pBR-pLac (TSS Transformation)

This work, KMT20172 + pBR-pLac-ryhB (TSS Transformation)

This work, KMT20172 + pBR-pLac-ryhBm1 (TSS Transformation)

This work, KMT20174 + pBR-pLac (TSS Transformation)

This work, KMT20174 + pBR-pLac-ryhB (TSS Transformation)

This work, KMT20174 + pBR-pLac-ryhBm3 (TSS Transformation)

PM1800 $\times \mathrm{P}_{B A D}$-rseA-3XFLAG w.t. amplified gBlock KT902 + KT1138

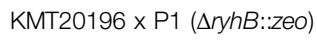


TABLE 2 | Plasmid list.

\section{Plasmid}

pBR-pLac pBR-pLac-ryhB pBR-pLac-ryhBm1 pBR-pLac-ryhBm2 pBR-pLac-ryhBm3 pBR-pLac-fnrS pBR-pLac-fnrS-I pBR-pLac-fnrS-॥ pBR-pLac-fnrS-III

\section{Characteristics}

pBR322 ori (pMB1), PLlaco promoter-based expression vector, bla $\left(\mathrm{Amp}^{\mathrm{R}}\right)$ ryhB gene cloned into the Aatll/EcoRI site of pBR-pLac ryhB C14G, C15G, C16G site-directed mutations in pBR-pLac-ryhB ryhB C18G, G19C, C20G, and G21C site-directed mutations in pBR-pLac-ryhB ryhB G21C, G22C, A23C, G24A, A25C, and A26C site-directed mutations in pBR-pLac-ryhB fnrS gene cloned into the Aatll/EcoRl site of pBR-pLac fnrS U57A, U58G, U59A site-directed mutations in pBR-pLac-fnrS fnrS C47A U48A U49G site-directed mutations in pBR-pLac-fnrS fnrS G4C, G5U site-directed mutation in pBR-pLac-fnrS

\section{References or source}

Guillier and Gottesman, 2006

Mandin and Gottesman (2009)

This work

This work

This work

Mandin and Gottesman (2009)

Gisela Storz, Durand and Storz (2010)

Gisela Storz, Durand and Storz, (2010) Gisela Storz, Durand and Storz (2010)

TABLE 3 | Oligonucleotide list.

Oligonucleotides

KT902

KT903

TAACGCCAGGGTITCCCAGTCACGACGTTGTAAAACGACTAAAGCGGAAAGTTGTTCTाCTGCAT

KT940

KT950

KT950c

KT951

KT951C

KT952

KT952c

KT953

KT953c

KT1115

KT1116

KT1137
GCACGACATTGCTCACCACACTTCCAGTATTACTTA

TAAGTAATACTGGAAGTGTGGTGAGCAATGTCGTGC

CATTGACATTGTGAGCGGATAACAAGATACT

CGAAGCGGCATGCATTACGTTG

CGTCGCGATCAGGAAGAGGGTCGCGGAGAACCTGAAA

TICAGGTTCTCCGCGACCCTCTTCCTGATCGCGACG

GCGATCAGGAAGACCCTGCGCGAGAACCTGAAAGCACG

CGTGCTTCAGGTCTCGCGCAGGGTCTTCCTGATCGC

GATCAGGAAGACCCTCGCCCCACCCCTGAAAGCACGACATTGGCACGACATTGCTCACCACACTTCCAGTATT

AATACTGGAAGTGTGGTGAGCAATGTCGTGCCAATGTCGTGCTICAGGGGTGGGGCGAGGGTCTTCCTGATC

CCGCATTAAAGCTTATCGATGATAAGCTG

CGCCAGGGTITCCCAGTCACGACGTTGTAAAACGACGGCTAAAGCGGAAAGTTGTTCTTCTGCAT

\section{Purpose}

forward primer for amplification of the $P_{B A D}$-rseA27-lacZ fusion recombination substrate reverse primer for amplification of the $P_{B A D}$-rseA27-lac $Z$ fusion recombination substrate Forward Screening primer for PM1205 fusions

forward primer for creation of ryhBm1 (C14G C15G C16G) by Quickchange mutagenesis reverse primer for creation of ryhBm1 (C14G C15G C16G) by Quickchange mutagenesis forward primer for creation of ryhBm2 (C18G G19C C20G G21C) for Quickchange mutagenesis reverse primer for creation of ryhBm2 (C18G G19C C20G G21C) for Quickchange mutagenesis

forward primer for creation of ryhBm3 (G22C G23C A24C G25A A26C A27C) for Quickchange mutagenesis reverse primer for creation of ryhBm3 (G22C G23C A24C G25A A26C A27C) for Quickchange mutagenesis forward primer for creation of ryhBm4 (A51C T52A T53C G54A) for Quickchange mutagenesis reverse primer for creation of ryhBm4 (A51C T52A T53C G54A) for Quickchange mutagenesis pBR-pLac forward screening and sequencing primer pBR-pLac reverse screening and sequencing primer reverse primer for amplification of the $P_{B A D}$-rseA27-lac $Z$ (wildtype and mutant) fusion recombination substrate 
TABLE 4 | List of synthetic DNA used in genetic engineering.

\begin{tabular}{|c|c|}
\hline $\begin{array}{l}\text { Sequence } \\
\text { name }\end{array}$ & Sequence \\
\hline $\begin{array}{l}\text { BAD-rseA27- } \\
c Z \text { gBlock }\end{array}$ & $\begin{array}{l}\text { AcctgacgcttttatcgcaactctctactgtttctccaTGAGACAGATAGTITCCGAACTATTGAGTCCCTCCCGGAAGATTACGCA } \\
\text { TGGCAATAACCTTGCGGGAGCTGGATGGCCTGAGCTATGAAGAGATAGCCGCTATCATGGATTGTCCGGTAGGTA } \\
\text { CGGTGCGTCACGTATCTTCCGAGCGAGGGAAGCTATTGATAACAAATTCAACCGCTTATCAGGCGTTGACGATAGC } \\
\text { GGGATACTGGATAAGGGTATAGGCatgCAGAAAGAACAACTTCCGCTTAGCCGTCGTITACAACGTCGTGACTG } \\
\text { GGAAAACCCTGGCG }\end{array}$ \\
\hline $\begin{array}{l}\mathrm{P}_{B A D^{-}} \\
\text {rseA27cm1- } \\
\text { lacZ gBlock }\end{array}$ & $\begin{array}{l}\text { AcctgacgcttttatcgcaactctctactgtttctccaTGAGACAGATAGTITCCGAACTATTGAGTCCCTCCCGGAAGATTACGCA } \\
\text { TGGCAATAACCTTGCGGGAGCTGGATGGCCTGAGCTATGAAGAGATAGCCGCTATCATGGATTGTCCGGTAGGTA } \\
\text { CGGTGCGTTCACGTATCTTCCGAGCGACCCAAGCTATTGATAACAAAGTCAACCGCTTATCAGGCGTGACGATAGC } \\
\text { GGGATACTGGATAAGGGTATTAGGCatgCAGAAAGAACAACTTCCGCTTAGCCGTCGTITACAACGTCGTGACTG } \\
\text { GGAAAACCCTGGCG }\end{array}$ \\
\hline $\begin{array}{l}\mathrm{P}_{B A D^{-}} \\
\text {rseA27cm3- } \\
\text { lacZ gBlock }\end{array}$ & $\begin{array}{l}\text { AcctgacgcttttatcgcaactctctactgtttctccaTGAGACAGATAGTITCCGAACTATTGAGTCCCTCCCGGAAGATTACGCA } \\
\text { TGGCAATAACCTTGCGGGAGCTGGATGGCCTGAGCTATGAAGAGATAGCCGCTATCATGGATTGTCCGGTAGGTA } \\
\text { CGGTGCGTTCACGGAGTGGGCGAGCGAGGGAAGCTATTGATAACAAAGTCAACCGCTIATCAGGCGTTGACGAT } \\
\text { AGCGGGATACTGGATAAGGGTATTAGGCatgCAGAAAGAACAACTICCGCTITAGCCGTCGTITACAACGTCGTGA } \\
\text { CTGGGAAAACCCTGGCG }\end{array}$ \\
\hline
\end{tabular}

$P_{B A D}-r S e A-$ 3XFLAG gBlock

AcctgacgctttttatcgcaactctctactgtttctccaTGAGACAGATAGTTTCCGAACTATTGAGTCCCTCCCGGAAGATT ACGCATGGCAATAACCTTGCGGGAGCTGGATGGCCTGAGCTATGAAGAGATAGCCGCTATCATGGATTGTCCGGTAG GTACGGTGCGTTCACGTATCTTCCGAGCGAGGGAAGCTATTGATAACAAAGTTCAACCGCTTATCAGGCGTTGACGA TAGCGGGATACTGGATAAGGGTATTAGGCatgCAGAAAGAACAACTTTCCGCTITAATGGATGGCGAAACGCTGGATA GTGAGCTGCTTAACGAACTGGCTCATAACCCAGAAATGCAGAAAACCTGGGAAAGCTATCACTTAATCCG TGACTCAATGCGGGGTGATACTCCCGAGGTGCTCCATTTCGATATCTCTTCACGCGTGATGGCCGC CATTGAAGAAGAGCCAGTACGTCAACCGGCGACATTGATCCCGGAAGCCCAGCCTGCGCC GCATCAATGGCAGAAAATGCCATTCTGGCAGAAAGTACGTCCGTGGGCGGCACAGCTTACCCAAATGGGCGTAGC CGCATGCGTATCGCTTGCAGTTATCGTTGGCGTCCAGCACTATAATGGACAATCTGAAACGTCCCAGCAGCC CGAAACGCCGGTATTTAATACACTGCCGATGATGGGTAAAGCCAGCCCGGTAAGCCTGGGAGTACCTTCTGAAGCG ACCGCAAACAATGGTCAACAGCAGCAGGTACAGGAGCAGCGTCGTCGCATTAATGCAATGTTGCAGGATTACG AACTGCAACGCCGACTCCACTCTGAACAGCTTCAGTTTGAGCAGGCGCAAACCCAGCAAGCCGCTGTACAG GTGCCAGGAATTCAAACTITAGGAACGCAATCGCAGGATTACAAAGATCATGACGGGGACTACAAAGA TCACGATATAGATTATAAAGATGACGATGACAAAtaaATTATAAAAATTGCCTGATACGCTGCGCTTATCAGGCCTA

$P_{B A D^{-}} \quad$ AcctgacgcttttatcgcaactctctactgttctccaTGAGACAGATAGTITCCGAACTATTGAGTCCCT

rseAcm1- CCCGGAAGATTTACGCATGGCAATAACCTTGCGGGAGCTGGATGGCCTGAGCTATGAAGA

3XFLAG GATAGCCGCTATCATGGATTGTCCGGTAGGTACGGTGCGTTCACGTATCTTCCGAGCG

gBlock
ACCCAAGCTATTGATAACAAAGTTCAACCGCTTATCAGGCGTTGACGATAGCGGG

ATACTGGATAAGGGTATTAGGCatgCAGAAAGAACAACTTCCGCTITAATGGATGGCGA

AACGCTGGATAGTGAGCTGCTTAACGAACTGGCTCATAACCCAGAAATGCAGAAAACCTG

GGAAAGCTATCACTTAATCCGTGACTCAATGCGGGGTGATACTCCCGAGGTGCTCCATTI

CGATATCTCTTCACGCGTGATGGCCGCCATTGAAGAAGAGCCAGTACGTCAACCGGCGACAT

TGATCCCGGAAGCCCAGCCTGCGCCGCATCAATGGCAGAAAATGCCATTCTGGCAGAA

AGTACGTCCGTGGGCGGCACAGCTTACCCAAATGGGCGTAGCCGCATGCGTATCGCTTGCAGTTATCGTTGGCGTCC AGCACTATAATGGACAATCTGAAACGTCCCAGCAGCCCGAAACGCCGGTATTTAATACACTGCCGATGATGGGTAA AGCCAGCCCGGTAAGCCTGGGAGTACCTTCTGAAGCGACCGCAAACAATGGTCAACAGCAGCAGGTACAGGAG CAGCGTCGTCGCATTAATGCAATGTTGCAGGATTACGAACTGCAACGCCGACTCCACTCTGAACAGCTTCAGTT TGAGCAGGCGCAAACCCAGCAAGCCGCTGTACAGGTGCCAGGAATTCAAACTTIAGGAACGCAATCGCAGGA TTACAAAGATCATGACGGGGACTACAAAGATCACGATATAGATTATAAAGATGACGATGACAAAtaaATTATAA AAATTGCCTGATACGCTGCGCTTATCAGGCCTA

Purpose

used as a template for amplification of the recombination substrate for creation of $\mathrm{P}_{B A D}$-rSeA27lacZ translational fusion

used as a template for amplification of the recombination substrate for creation of $\mathrm{P}_{B A D^{-}}$ rseA27(cm1)-lacZ translational fusion

used as a template for amplification of the recombination substrate for creation of $\mathrm{P}_{B A D^{-}}$ rseA27(cm3)-lacZ translational fusion used as a template for amplification of recombination substrate for creation of $\mathrm{P}_{B A D}-r \mathrm{se} A$ 3XFLAG

\author{
used as a template for \\ amplification of \\ recombination substrate for
creation of $\mathrm{P}_{B A D}$-rseAcm1- \\ recombination substrate for
creation of $\mathrm{P}_{B A D}$-rseAcm1- \\ 3XFLAG
}

$30^{\circ} \mathrm{C}$ and then shifted $43.5^{\circ} \mathrm{C}$ to induce expression of $\lambda$-Red proteins. Transformants were grown on LB agar plates supplemented with ampicillin, to a final concentration of $100 \mu \mathrm{g} / \mathrm{ml}$. Zeomycin-resistant recombinants or transductants were selected on LB agar plates supplemented with Zeocin ${ }^{\mathrm{TM}}$ (or zeomycin) to a final concentration of $25 \mu \mathrm{g} / \mathrm{ml}$. Small RNA screens were executed on MacConkey-Lactose (Mac-Lac) agar plates supplemented with ampicillin, to a final concentration of $100 \mu \mathrm{g} / \mathrm{ml}$, and arabinose to a final concentration of $0.02 \%$ or $0.00002 \%$. All gene fusions were created as previously described using recombineering and selecting for recombinant fusions on M63 minimal salt agar plates supplemented with glycerol, $6 \%$ sucrose, and $80 \mu \mathrm{g} / \mathrm{ml}$ of $\mathrm{X}$-gal at $30^{\circ} \mathrm{C}$ (Mandin and Gottesman, 2009). For iron starvation experiments, cultures were grown in LB media in a shaking water bath at $37^{\circ} \mathrm{C}$ to an $\mathrm{OD}_{600}$ of 0.3 and then treated with 2'2-dipyridyl (Sigma Aldrich) to a final concentration of $250 \mu \mathrm{M}$ for $30 \mathrm{~min}$. For RNA stability assays, rifampicin was added to bacterial cultures to a final concentration of $250 \mu \mathrm{g} / \mathrm{ml}$. 


\section{Bacterial Strains, Plasmids, and Genetic Constructs}

All strains used for experiments conducted in this study were derivatives of Escherichia coli K-12 MG1655. Cloning reactions were executed in MC1061 or NEB5a (New England Biolabs). All strains are listed in Table 1. All plasmids used in this study are listed in Table 2. All oligonucleotides used for polymerase chain reaction (PCR)-mediated genetic engineering, PCR screening, or Northern blot analysis are listed in Table 3. $\lambda$-Red recombineering reactions to gene fusions were executed in strain PM1800. PM1800 has a cat-sacB cassette inserted in the lac locus and encodes the $\lambda$-Red proteins ( $\mathrm{gam}$, exo, and beta) on a partial lambda vector marked with tetracycline resistance (mini- $\lambda$ :tet). Plasmids from the small RNA library or their respective mutants were transformed into the $\mathrm{P}_{B A D^{-}}$rseA27-lacZ translational fusion strain using TSS transformation (Chung et al., 1989). Mutations were transduced into reporter fusion strains using Bacteriophage P1 transduction.

\section{Construction of $\mathrm{P}_{B A D}-$ rseA27-lac $Z$ and Translational Fusion and $\mathrm{P}_{B A D}-r s e A-3 X F L A G$ Strains}

In order to execute our screen for small RNA regulation of the rse $A B C$ operon, we first created an arabinose-inducible in-frame translational fusion of the first nine codons of the rseA gene (rseA27) to the ninth codon of lacZ via recombineering into strain PM1800 as previously described (Mandin and Gottesman, 2009). We also created a 3XFLAG-tagged allele of the entire $r$ seA gene at the lac locus using the same recombineering method (Mandin and Gottesman, 2009). All the fusions contained the entire $5^{\prime}$ UTR of the $r s e A B C$ transcript (Figure 1A) immediately downstream from the arabinose-inducible araBAD promoter $\left(\mathrm{P}_{B A D}\right)$. To create the allelic exchange substrates for either the $\mathrm{P}_{B A D^{-}}$rseA27-lacZ, $\mathrm{P}_{B A D^{-}}$rseA27cm1-lacZ, $\mathrm{P}_{B A D^{-}}$rseA27cm3lac $Z$, or $\mathrm{P}_{B A D^{-r s e}}$-3XFLAG, or $\mathrm{P}_{B A D^{-}} r s e A c m 1-3 X F L A G$ fusions, we amplified synthetic DNA gBlocks (IDT DNA) corresponding to each fusion using oligonucleotide primers KT902 and KT903. All synthetic DNA sequences used for genetic engineering of gene fusions are listed in Table 4. All oligonucleotide primers used for PCR reactions are listed in Table 3. We confirmed the presence of the lac $Z$ translational fusion inserts by PCR using oligonucleotide primers KT940 and KT903 and DNA sequencing. We confirmed the presence of the 3XFLAG tagged alleles by PCR using oligonucleotide primers KT902 and KT1136 and DNA sequencing.

\section{Site-Directed Mutagenesis of pBR-pLac-ryhB}

We used the QuikChange ${ }^{\circledR}$ Site-Directed Mutagenesis Kit (Stratagene), according to the manufacturer's recommendations to create ryhB point mutants. Mutagenic primers used for the PCR reaction are listed in Table 3. Point mutants were verified by DNA sequencing.

\section{$\beta$-Galactosidase Assays}

Overnight cultures were grown in Lennox Broth (LB) supplemented with ampicillin and glucose to a final concentration of $100 \mu \mathrm{g} / \mathrm{ml}$ and $0.2 \%$, respectively, at $37^{\circ} \mathrm{C}$. The cultures were diluted 1:1000 in fresh Lennox Broth (LB) supplemented with ampicillin and arabinose to a final concentration of $100 \mu \mathrm{g} / \mathrm{ml}$ and $0.02 \%$, respectively. Once the culture reached an $\mathrm{OD}_{600}$ of $0.4-0.5$, a $100 \mu \mathrm{L}$ aliquot was taken for the $\beta$-galactosidase assay as previously described (Miller, 1992). Alternatively, $\beta$-galactosidase assays were executed in 96-well plates as previously described (Zhou and Gottesman, 1998).

\section{Western Blot Analysis}

Cell lysates were created as previous described (Ezemaduka et al., 2014). Briefly, cells were harvested and resuspended in $300 \mathrm{ul} \mathrm{of}$ $20 \mathrm{mM}$ Tris- $\mathrm{HCl}, \mathrm{pH} 8.0$, and lysed by sonication. The resulting cell lysates were centrifuged at $800 \times g$ for 5 -min to remove cell debris and unbroken cells. The supernatants for the respective samples were then transferred to new $1.5 \mathrm{ml}$ tubes and subjected to centrifugation at $1,000 \times g$ for $30 \mathrm{~min}$. The resulting supernatant (soluble proteins) and precipitate (aggregated proteins) from the second centrifugation were then quantified using a Lowry assay and placed on ice. Equivalent amounts of total protein were prepared and subjected to electrophoresis using a Bolt ${ }^{\mathrm{TM}} 12 \%$, Bis-Tris Protein Gel (Invitrogen), according to the manufacturer's instructions. The total proteins were then transferred to a $0.45 \mu \mathrm{m}$ pore-size nitrocellulose membrane using a Trans-Blot ${ }^{\circledR}$ Turbo $^{\text {TM }}$ System (BIO-RAD) for $10 \mathrm{~min}$ at $2.5 \mathrm{~A}$ and $25 \mathrm{~V}$. After the successful transfer, the membrane was washed briefly in a phosphate-buffered saline and Tween 20 (PBST) solution and then blocked at room temperature for $30 \mathrm{~min}$ in $0.5 \%$ Blotting-Grade nonfat milk dissolved in PBST. The membrane was incubated overnight with gentle shaking at $4^{\circ} \mathrm{C}$ in a 1 : 50,000 dilution of a primary antibody and $0.5 \%$ Blotting-Grade nonfat milk blocking solution. The membrane was washed with PBST three times for 5 min each and incubated with gentle shaking in a 1:50,000 dilution of a secondary antibody and $0.5 \%$ Blotting-Grade nonfat milk blocking solution for $2 \mathrm{~h}$. The signal was developed using a Novex AP Chemiluminescent Kit according to the manufacturer's recommendations (Thermofisher Scientific). The protein signals were visualized using the FluorChem R imager (Protein Simple).

\section{Northern Blot Analysis}

Total RNA was isolated using the hot acid phenol method as previously described (Aiba et al., 1981). RNA stability assays were performed as previously described using hot phenol following culture treatment with rifampicin to a final concentration of $250 \mu \mathrm{g} / \mathrm{ml}$ (Masse et al., 2003). Total RNA from each sample was mixed with the 10X RNA gel loading dye (National Diagnostics), 10X MOPS buffer, 100\% formaldehyde, and $100 \%$ formamide and heated at $65^{\circ} \mathrm{C}$ for $15 \mathrm{~min}$. The samples were loaded onto a $1 \%$ agarose gel and subjected to electrophoresis at $100 \mathrm{~V}$ for $40 \mathrm{~min}$. The agarose gel was subjected to a nylon membrane capillary transfer. Following UV cross-linking, the membrane was prehybridized for $2 \mathrm{~h}$ using PerfectHyb ${ }^{\mathrm{TM}}$ Plus Hybridization Buffer (Sigma Aldrich). The membrane was then hybridized with a biotinylated DNA probe against RseA or 16S rRNA transcripts. (IDT DNA) for $4 \mathrm{~h}$ (Table 3). The membrane was washed with high, medium, and low stringency buffers and processed using a Chemiluminescent Detection Kit (Lifetechnologies) according to the manufacturer's recommendation. The chemiluminescent signal was detected using Fluorochem E (Protein Simple).

\section{Statistical Analysis}

All statistical analyses were executed using GraphPad Prism version 9 (GraphPad). 


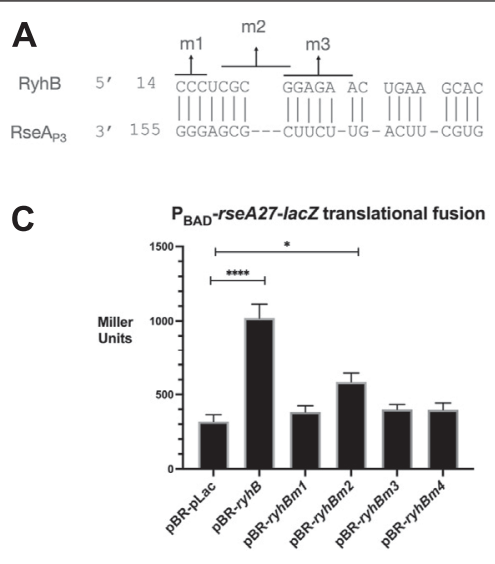

E

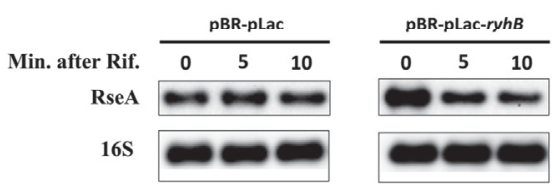

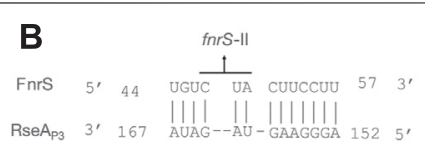

D $P_{\mathrm{BAD}}$-rseA27-lacZ translational fusion

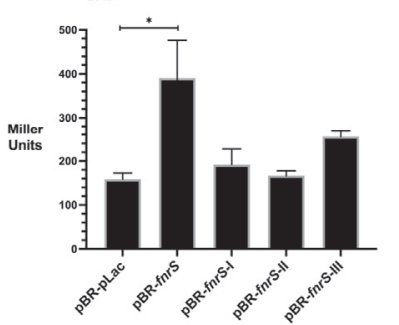

$\mathbf{F}$

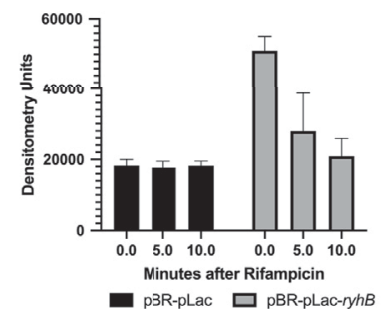

FIGURE 2 | RyhB/FnrS pairing with RseA and $\beta$-galactosidase assays (A). Regions of predicted base pairing between the RyhB and RseA sequences were determined using the online computational tool IntaRNA 2.0. Point mutants in the small RNA used for interaction analysis were denoted as $\mathrm{m1}$ (C14G, C15G, C16G), m2 (C18G, G19C, C20G, and G21C), or m3 (G21C, G22C, A23C, G24A, A25C, and A26C) (B). $\Delta r y h B ~ \Delta f n r S P_{B A D}$-rseA27-lacZ translational fusions containing pBR-pLac, pBR-ryhB, pBR-pLac-ryhBm1, pBR-pLac-ryhBm2, or pBR-pLac-ryhBm3 were grown in rich media to an $\mathrm{OD}_{600}$ of 0.5 , and aliquots were isolated for the $\beta$-galactosidase assay (C). Regions of predicted base pairing between FnrS small RNA and the $5^{\prime}$ UTR of RseA were determined using the online computational tool IntaRNA 2.0. One of the fnrS point mutants tested occurs in the region of pairing shown (B). $\Delta r y h B \Delta f n r S P_{B A D}-r s e A 27-l a c Z$ translational fusions containing pBR-pLac, pBR-ryhB, pBR-pLac-ryhBm1, pBR-pLac-ryhBm2, or pBR-pLac-ryhBm3 were grown in rich media to an $\mathrm{OD}_{600}$ of 0.5 , and aliquots were isolated for the $\beta$-galactosidase assay (D). $\Delta r y h B \Delta f n r S P_{B A D}-r s e A 27-l a c Z$ translational fusions containing pBR-pLac, pBR-fnrS, pBR-pLac-fnrS-I, pBR-pLac-fnrS-II, or pBR-pLacfnrS-III were grown in rich media to an $\mathrm{OD}_{600}$ of 0.5 , and aliquots were isolated for the $\beta$-galactosidase assay $(\mathbf{E})$. $\mathrm{P}_{B A D}$-rseA27-lacZ translational fusions were grown to the mid-exponential phase and induced with arabinose and IPTG to a final concentration of $0.2 \%$ and $1 \mathrm{mM}$, respectively. Cultures were then treated with rifampicin, and total RNA was isolated at 5 and 10 min following rifampicin treatment. RNA was subjected to northern blot analysis using a biotinylated RseA probe (F). Densitometric analysis of northern blot is shown in Panel E. All $\beta$-galactosidase assays and densitometry assays were executed in triplicate and are represented as averages \pm the standard error of the mean (SEM). Statistical significance was assessed by one-way ANOVA with Dunnett's post hoc test $\left({ }^{\star} p<0.05,{ }^{\star \star \star \star} p<0.0001\right)$.

\section{RESULTS}

\section{RyhB and FnrS were Picked up in a Genetic Screen for Small RNA Regulators of RseA Expression}

The start site of the $r s e A_{\mathrm{P} 3}$ promoter is 228 nucleotides upstream from the rseA start codon. The 228 nucleotide 5 ' UTR likely forms a secondary structure that influences translational initiation in concert with small RNAs. We therefore hypothesized that the $r s e A B C$ operon, driven by the $r s e A_{\mathrm{P} 3}$ promoter, was regulated at the post-transcriptional level by a small RNA. In order to determine if the $r s e A_{\mathrm{P} 3}$ transcript was regulated by a small RNA, we constructed an arabinose-inducible $r s e A$ lac $Z$ translational gene fusion (Figure 1A). We then transformed the $\mathrm{P}_{\mathrm{BAD}}$-rseA27-lacZ translational fusion strain with a plasmid based small RNA library as previously described (Mandin and Gottesman, 2009). This small RNA library contains 30 of the most extensively characterized E. coli small RNAs cloned downstream of an isopropyl $\beta$-d-1-thiogalactopyranoside (IPTG)-inducible promoter (Mandin and Gottesman, 2009). We executed the small RNA library screen on
MacConkey-Lactose (Mac-Lac) agar plates supplemented with ampicillin to a final concentration of $100 \mu \mathrm{g} / \mathrm{ml}$ and arabinose to a final concentration of $0.0002 \%$. This arabinose concentration was sufficient to induce basal transcription from the $\mathrm{P}_{\mathrm{BAD}}$ promoter without producing a strong $\mathrm{Lac}^{+}$ phenotype. The concentration of lactose in the Mac-Lac plates was sufficient to induce small RNA expression from the IPTG-inducible promoter. We hypothesized that this screening condition was ideal for the possible identification of stimulatory small RNAs. Two of the 30 plasmids, carrying RyhB or FnrS, resulted in an increased Lac phenotype (Figure 1B), suggesting that RyhB and FnrS promote posttranscriptional expression of RseA.

\section{RyhB and FnrS Point Mutants are Defective in Stimulating RseA Expression}

To validate the results of our genetic screen, we executed computational analysis to identify regions of potential complementary base pairing between RyhB or FnrS and the 

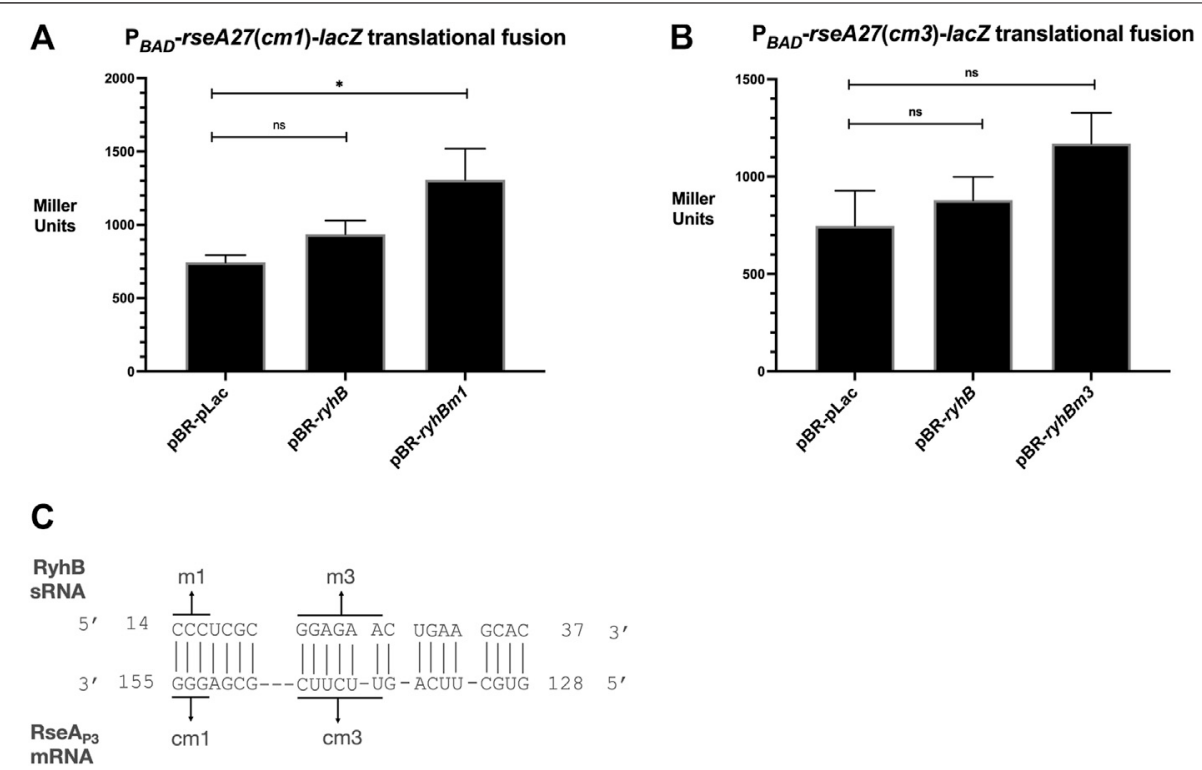

FIGURE 3 | RyhB-RseA compensatory mutational analysis (A). The $\mathrm{P}_{B A D}-r s e A 27 \mathrm{~cm} 1$-lacZ translational fusion strain transformed with pBR-pLac, pBR-pLac-ryhB, or pBR-pLac-ryhBm 1 was grown to the mid-log phase $\left(\mathrm{OD}_{600}\right.$ of 0.5$)$ in LB supplemented with ampicillin and arabinose to final concentrations of $100 \mu \mathrm{g} / \mathrm{ml}$ and $0.02 \%$, respectively, and $100 \mu \mathrm{L}$ aliquots were isolated for the $\beta$-galactosidase assay (B). The $\mathrm{P}_{B A D}-r s e A 27 \mathrm{~cm} 3-l a c Z$ translational fusion strain transformed with pBR-pLac, pBR-pLac-ryhB, or pBR-pLac-ryhBm3 was grown to the mid-log phase $\left(\mathrm{OD}_{600}\right.$ of 0.5$)$ in LB supplemented with ampicillin and arabinose to final concentrations of $100 \mu \mathrm{g} / \mathrm{ml}$ and $0.02 \%$, respectively, and $100 \mu \mathrm{L}$ aliquots were isolated for the $\beta$-galactosidase assay (C). Putative nucleotide interactions between RyhB and RseA tested with RyhB mutants and RseA compensatory mutants. All $\beta$-galactosidase assays were executed in triplicate and are represented as averages \pm SEM. Statistical significance was assessed by one-way ANOVA with Dunnett's post hoc test $\left({ }^{*} p<0.05\right)$.

RseA leader region (Figures 2A,B). Specifically, we screened the RyhB and FnrS sequences against the Rse $\mathrm{A}_{\mathrm{P} 3} 5^{\prime}$ UTR sequence using IntaRNA 2.0. For RyhB, we identified a semi-continuous stretch of nucleotides between $\mathrm{C} 14$ and $\mathrm{C} 37$ with complementarity to RseA $A_{P 3}$ G128 to G155 (Figure 2A). The longest stretch of complementarity was seven base pairs between RyhB C14 to RyhB C20 and RseA G148 to G155. For FnrS, we identified a semi-continuous stretch of nucleotides between U44 and U57 with complementarity to RseA $\mathrm{P}_{3}$ A152 and A167 (Figure 2B). The longest stretch of which was a seven base pair region of complementarity between FnrS C51 to U57 and RseA A152 to G158 (Figure 2B). We then created nucleotide point mutants in the plasmid-based RyhB construct that would disrupt the predicted complimentary base pairing between RyhB and RseA (Figure 2A). The RyhB point mutants consist of the following changes: $\mathrm{m} 1 \mathrm{C} 14 \mathrm{G}$, C15G, C16G), m2 (C18G, G19C, C20G, and G21C), and m3 (G21C, G22C, A23C, G24A, A25C, and A26C) (Figure 2A). The FnrS point mutants were previously described and consist of the following changes: fnrS-I (U57A, U58G, U59A), fnrS-II (C47A U48A U49G), and fnrS-III (G4C, G5U) (Durand and Storz, 2010).

In order to determine if the RyhB nucleotides predicted to pair with RseA are necessary for RseA stimulation, we determined the activity of the $\mathrm{P}_{B A D}$-rseA27-lac $Z$ translational fusion upon over-expression of wild type and mutant alleles of RyhB. We executed these assays in a $r y h B^{-} f n r S^{-}$genetic background to ensure that the plasmids were the only source of RyhB or FnrS expression. We grew all strains in LB (Lennox) supplemented with ampicillin and arabinose to final concentrations of $100 \mu \mathrm{g} / \mathrm{ml}$ and $0.02 \%$, respectively. We then obtained $100 \mu \mathrm{L}$ aliquots of each culture in the mid-log phase of growth $\left(\mathrm{OD}_{600}\right.$ of 0.5$)$ and measured $\beta$-galactosidase activity. As expected, plasmid-based $\mathrm{RyhB}$ induced $\mathrm{P}_{B A D^{-}}$rseA27-lac $Z$ activity by approximately 3 -fold in comparison to the vector control (Figure 2C), while all RyhB point mutants were defective for stimulation of $\mathrm{P}_{B A D^{-}}$-seA27-lacZ (Figure 2C). This confirms the results of our genetic screen and suggests that RyhB stimulates post-transcriptional expression of RseA. Further, it suggests that RyhB nucleotides predicted to pair with nucleotides in the RseA leader region are necessary for RyhB post-transcriptional stimulation of RseA expression (Figure 2C). We executed a similar experiment using FnrS and a series of FnrS point mutants to determine if FnrS may stimulate the post-transcriptional expression of RseA. FnrS expression results in a 2 -fold increase in $\mathrm{P}_{B A D^{-}}$-rseA27-lac $Z$. Each of the FnrS point mutants were also defective for stimulation of $\mathrm{P}_{B A D}$-rseA27-lacZ. To determine if the RyhB stimulatory effect on $\mathrm{RseA}_{\mathrm{P} 3}$ expression was due to an increase in RseA mRNA stability, we tested the stability of the RseA-LacZ following over-expression of RyhB (Figures 2E,F). We observed a 2 -fold increase in RseA-LacZ mRNA levels prior to the initiation of mRNA stability measures. The change in RseA-LacZ mRNA levels is similar to the change in

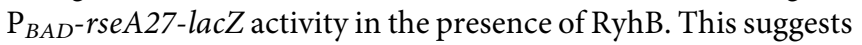
that RyhB stimulation of RseA post-transcriptional expression could occur at the level of transcription termination as previously described (Chen et al., 2019). 

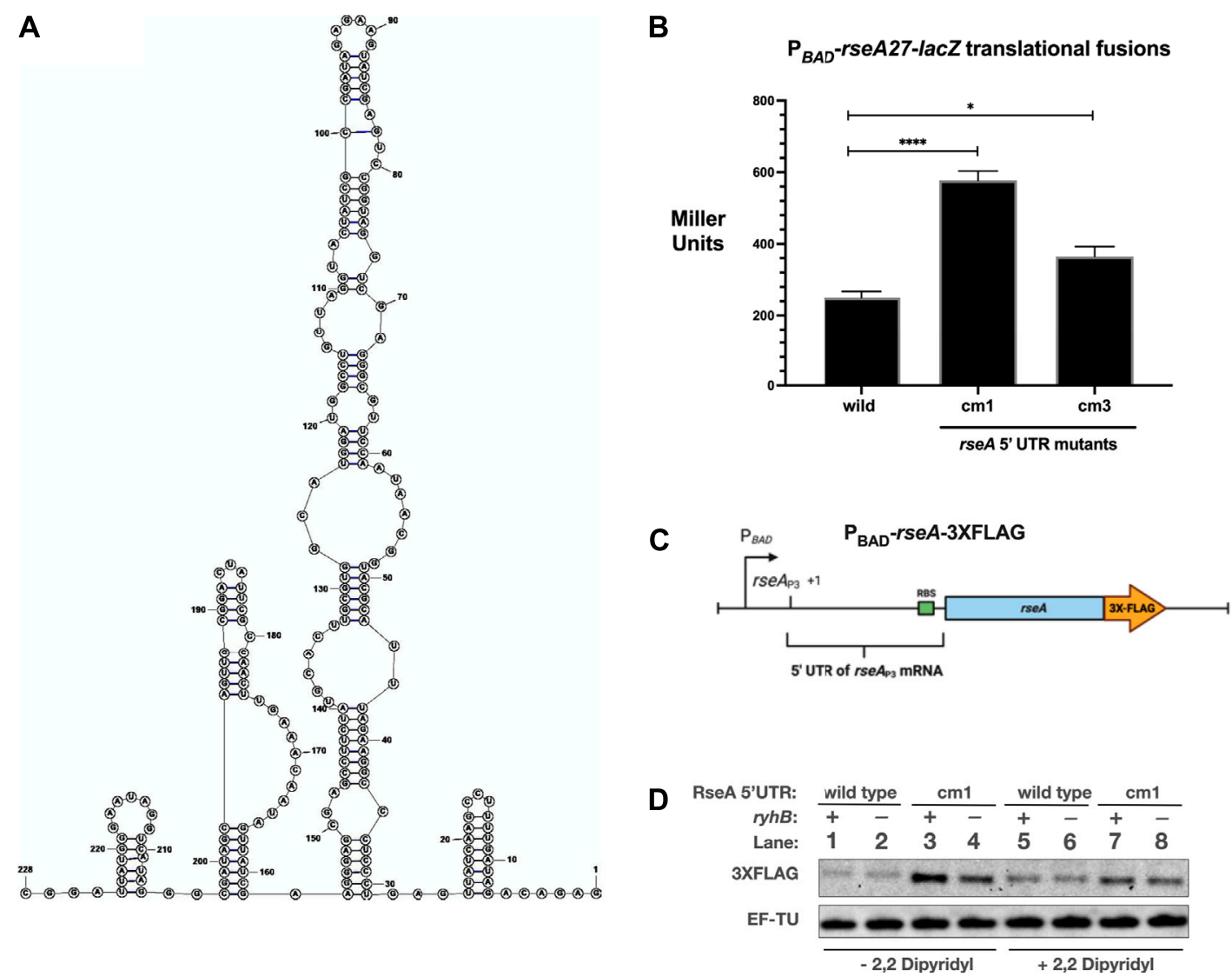

FIGURE 4 | 5' UTR mutations stimulate RseA translation (A). Predicted structure of RseA ${ }_{\mathrm{P} 3} 5^{\prime}$ UTR using RNAStructure (B). The wild-type, cm1, and cm3 alleles of

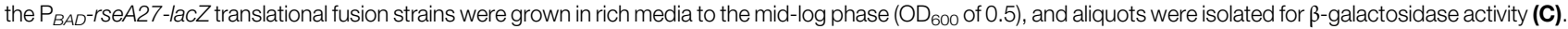
Schematic of the $P_{B A D}-r s e A-3 X F L A G$ allele utilized for the subsequent RseA-FLAG western blot (D). RseA-FLAG western blot. The wild-type and cm1 PBAD-rseA3XFLAG strains were grown in LB supplemented with arabinose to a final concentration of $0.002 \%$ to the mid-log phase and then treated with 2,2 -dipyridyl to a final concentration of $250 \mu \mathrm{M}$. Total proteins were isolated and subjected to western blot analysis using $\alpha$-FLAG. All $\beta$-galactosidase assays were executed in triplicate and are represented as averages \pm SEM. Statistical significance was assessed by one-way ANOVA with Dunnett's post hoc test $\left({ }^{\star} p<0.05\right.$, $\left.{ }^{\star \star \star \star} p<0.0001\right)$.

\section{Compensatory Mutations in RseA Suggest that RyhB Interacts with the RseA Leader Region}

In order to test the hypothesis that RyhB stimulates RseA through the direct interaction between complementary nucleotides, we designed putative compensatory nucleotide point mutations in the $5^{\prime} \mathrm{UTR}$ of $\mathrm{P}_{B A D^{-}}$rseA27-lacZ translational fusions that were predicted to restore the ability of RyhB $\mathrm{m} 1$ or RyhB m3 mutants to stimulate $\mathrm{P}_{\mathrm{BAD}}$-rseA27-lacZ activity (Figure $3 \mathrm{C}$ ). The $\mathrm{P}_{B A D^{-}}$ rseA27(cm1)-lacZ translational fusion contains G153C G154C G155C nucleotide point mutants within the RseA 5' UTR regions of the fusion, which were predicted to interact with the RyhB m1 allele (Figure 3C). The $\mathrm{P}_{B A D^{-}} r \mathrm{se} A 27$ ( $\mathrm{cm} 3$ )-lacZ allele contains U139G U141G C142U U143G U144G C145G nucleotide point mutants within the RseA $5^{\prime}$ UTR regions of the fusion, which were predicted to interact with the RyhBm3 allele (Figure $3 \mathrm{C}$ ). RyhB over-expression does not result in the stimulation of $\mathrm{cm} 1$ or $\mathrm{cm} 3$ mutants of the $\mathrm{P}_{B A D^{-}}$-seA27-lac $Z$ fusion (Figures $3 \mathbf{A}, \mathbf{B}$ ). However, the expression of the RyhBm1 mutant was able to stimulate the $\mathrm{P}_{B A D^{-}}$rse $A 27(\mathrm{~cm} 1)$-lacZ fusion, approximately 2fold in comparison to the vector control (Figure $\mathbf{3 A}$ ). In addition, the RyhBm3 allele was able to stimulate the $\mathrm{P}_{B A D^{-}}$rseA27(cm3)lac $Z$ fusion, approximately 2 -fold in comparison to the vector control (Figure 3B). These results suggest that RyhB activates post-transcriptional expression of RseA because of a direct interaction between RyhB and the RseA 5' UTR. Furthermore, this interaction requires RyhB C14 C15 C16 nucleotides and the RseA 5' UTR G153 G154 G155 nucleotides, as well as RyhB nucleotides G21, G22, A23, G24, A25, A26 and RseA nucleotides U139, U141, C142, U143, U144, C145 (Figure 3A).

\section{Optimal Post-Transcriptional Expression of RseA $_{P_{3}}$ is Inhibited by $\mathbf{5}^{\prime}$ UTR Sequences}

Since the RseA $\mathrm{P}_{\mathrm{P} 3}$ transcript is stimulated by RyhB and FnrS and RseA mRNA stability is not affected by RyhB over-expression, it is logical to assume that translation is repressed in the absence of the stimulatory small RNAs. Since the compensatory mutants in the RseA 5' UTR subdued the ability of RyhB to stimulate RseA 
translation, we hypothesized that the $\mathrm{cm} 1$ and $\mathrm{cm} 3$ mutations would result in increased post-transcriptional expression of RseA in the absence of stimulatory RNAs RyhB and FnrS (Figures 2, 3A,B). The $5^{\prime}$ UTR sequence of the Rse $A_{P 3}$ transcript was analyzed using the RNAStructure program. The predicted secondary structure contains several hairpins that may affect translation efficiency and accessibility of the RseA Shine Delgado sequence (Figure 4A). To test the hypothesis that the RseA compensatory mutant alleles have higher expression than wild-type alleles, we measured the activity of wild-type, $\mathrm{cm} 1$, and $\mathrm{cm} 3$ alleles of the $\mathrm{P}_{B A D}$-rseA27-lacZ translational fusion in the mid-log phase in rich media (Figure 4B). Both $\mathrm{cm} 1$ and $\mathrm{cm} 3$ alleles had higher $\beta$-galactosidase activity than the wild-type fusion (Figure 4B). The activity of the $\mathrm{P}_{B A D^{-}}$rseA27(cm3)-lacZ translational fusion was approximately 3 -fold higher than the activity of the wild-type $\mathrm{P}_{B A D^{-}} r$ seA27-lacZ translational fusion (Figure 4B). The activity of the $\mathrm{P}_{B A D}$-rseA27 (cm3)-lacZ translational fusion was approximately 1.5-2-fold higher than the activity of the wild-type $\mathrm{P}_{B A D}$-rseA27-lac $Z$ translational fusion (Figure 4B). We also created a chromosomal 3XFLAG epitope-tagged allele of $r s e A$, driven by an arabinose inducible promoter, to measure post-transcriptional expression of the $\mathrm{RseA}_{\mathrm{P} 3}$ transcript in a manner that uncouples its synthesis from envelope stress $\left(\mathrm{P}_{B A D^{-}} r s e A-3 \mathrm{XFLAG}\right.$ at the lac locus-Figure $4 \mathrm{C}$ ). We also created a $\mathrm{cml}$ allele of the $\mathrm{P}_{B A D^{-}}$ rseA-3XFLAG allele. This would allow us to determine if the RseA $5^{\prime}$ UTR mutations that increase $\mathrm{P}_{B A D^{-} \text {-rseA27-lac } Z \text { activity }}$ correspond to increased RseA protein levels. We then grew $\left(r y h B^{+}\right.$and $\left.r y h B^{-}\right)$wild-type and $\mathrm{cm} 15^{\prime}$ UTR alleles of $\mathrm{P}_{\mathrm{BAD}^{-}}$ rseA-3XFLAG in rich media supplemented with $0.002 \%$ arabinose to induce RseA-3XFLAG expression. At the midlogarithmic phase, cultures were treated with 2,2-dipyridyl for $30 \mathrm{~min}$ to deplete iron and induce RyhB expression. We then isolated total protein and measured RseA-FLAG expression. RseA-FLAG levels were increased by at least 3fold in the $\mathrm{cm} 15^{\prime}$ UTR genetic background compared to the wild-type $5^{\prime}$ UTR genetic background (Figure 4D, lane 3 vs lane $1)$, consistent with our $\beta$-galactosidase assay results in Figure 4B. This further supports the idea that the wild-type sequence of the Rse $A_{P 3} 5^{\prime}$ UTR contains secondary structures that prevent optimal translation. Also, the absence of $r y h B$ in the $\mathrm{cm} 15^{\prime}$ UTR genetic background resulted in a 3-fold decrease in RseA-FLAG protein levels from cells grown in rich media without 2,2-dipyridyl supplementation (Figure 4D, lane 4 vs lane 3 ). This suggests that the $\mathrm{cm} 1$ mutation is not sufficient for complete inhibition of RyhB stimulation of RseA expression. Unexpectedly, we did not see this difference in RseA-FLAG protein levels isolated from cells grown in rich media supplemented with 2,2-dipyridyl. In addition, the absence of $r y h B$ did not change RseA-FLAG protein levels in the wild-type 5' UTR genetic background for cells grown in rich media without 2,2-dipyridyl, whereby RyhB levels are not expected to be repressed by Fur. (Figure 4D, lanes 1 and 2). Unexpectedly, for reasons that are not clear, the absence of $r y h B$ had no noticeable effect on the stimulation of RseA-FLAG protein levels under iron starvation conditions (Figure 4D, lanes 5 and 6).

\section{DISCUSSION}

Optimal levels of $\sigma^{\mathrm{E}}$ are critically important for a functional ESR. The absence of $\sigma^{\mathrm{E}}$ precludes the initiation of the ESR. Excess $\sigma^{\mathrm{E}}$ results in aberrant cell physiology and ultimately cell death (Nitta et al., 2000; Kabir et al., 2005). Fine tuning the synthesis and activity of $\sigma^{\mathrm{E}}$ is the major tool that the cell uses in order to achieve this goal. The $r p o E$ operon includes several negative regulators of $\sigma^{\mathrm{E}}$ activity: $r s e A, r s e B$, and $r s e C$, in addition to the $r p o E$ leader peptide $r s e D$ (Klein et al., 2016). This particular operon has several promoters controlled by several transcriptional regulators and sigma factors, responding to a multitude of conditions (Klein et al., 2016). Since the negative regulators of $\sigma^{\mathrm{E}}$ are cistronic to $r p o E$, a negative feedback loop for $\sigma^{\mathrm{E}}$ activity is built into the synthesis of $r p o E$. The $r s e A_{\mathrm{P} 3}$ promoter drives the transcription of the rseA-rseB-rseC operon (Rhodius et al., 2006). Since this operon differs from the $r p o E$ operon only in the absence of the rseD and $r p o E$ genes, it suggests that secondary synthesis of the negative regulators of $\sigma^{\mathrm{E}}$ activity are necessary under conditions that are unique and separate from conditions driving the synthesis of the $r p o E$ operon. The $r s e A_{\mathrm{P} 3}$ promoter and one of the several promoters of the $r p o E$ operon are $\sigma^{\mathrm{E}}$-dependent. This highlights the regulatory redundancy in the $\sigma^{\mathrm{E}}$-dependent synthesis of RseA at the level of transcriptional initiation (Rhodius et al., 2006; Klein et al., 2016). This redundancy is likely reconciled through posttranscriptional regulation of $r p o E_{\mathrm{P}}$ and $r s e A_{\mathrm{P} 3}$ transcripts via mechanisms described in this work and additional regulatory switches that are undiscovered (Yakhnin et al., 2017). Genetic analysis of the $\mathrm{P}_{B A D^{-}}$rseA27-lacZ translational fusion, RseAFLAG protein levels from a $\mathrm{P}_{B A D^{-}} r s e A-3 X F L A G$ epitopetagged allele, suggests that the wild-type sequence of the RseA $_{\mathrm{P} 3} 5^{\prime}$ UTR prevents optimal RseA expression (Figure 3), presumably through RNA secondary structures that prevent efficient translation or promoting degradation of the Rse $\mathrm{A}_{\mathrm{P} 3}$ transcript. This likely promotes tight control of RseA levels, specifically preventing excess of RseA levels in response to $\sigma^{\mathrm{E}}$ activity. However, the existence of the $r s e A_{\mathrm{P} 3}$ transcript driven by $\sigma^{\mathrm{E}}$-dependent promoters suggests that under specific conditions in concern with the $\sigma^{\mathrm{E}}$-dependent ESR, the cell requires the synthesis of additional RseA to prevent excess activity of $\sigma^{\mathrm{E}}$, which is deleterious in nature. The presence of a relatively long $5^{\prime}$ UTR, with a secondary structure suboptimal for the promotion of posttranscriptional expression, is an ideal cognate partner for one or more small regulatory RNAs. While a direct interaction with RseA is necessary for the posttranscriptional regulatory effect of RyhB, its precise molecular mechanism is not clear but a part of an ongoing investigations in our lab. The difference in RyhB-dependent RseA-LacZ mRNA decay rates suggests that a complicated mechanism of action may occur. Possible pathways for the RyhB regulatory effect on RseA include modulation of translation initiation or transcription termination.

We identified RyhB and FnrS as small RNAs with positive regulatory effects on RseA synthesis using a targeted genetic screen of a small RNA library. FnrS expression is induced in response to 
oxygen limitation (Durand and Storz, 2010). RyhB is expressed under iron-limiting conditions upon de-activation of the Fur repressesor (Masse and Gottesman, 2002). RyhB was also previously identified as a binding partner for RseA using the RNA interaction by ligation and sequencing (RIL-seq) (Melamed et al., 2016). RyhB is known to repress post-transcriptional expression of a host of genes, including iron sulfur cluster proteins involved in the tricarboxylic acid cycles, in response to iron limitation (Masse and Gottesman, 2002; Masse et al., 2003; Semsey et al., 2006; Desnoyers and Masse, 2012; Wright et al., 2013). There is at least one positive regulatory target for RyhB, the shikimate permease gene ShiA (Prevost et al., 2007). FnrS has several regulatory targets, all of which are negative regulatory targets (Boysen et al., 2010; Durand and Storz, 2010; Wright et al., 2013). The observations in this work expand the RyhB regulon by adding a second positive regulatory target. This work also expands the FnrS regulon by uncovering the first positive regulatory target of FnrS. RyhB and FnrS share three unique targets, SodA, SodB, and MarA (Masse and Gottesman, 2002; Afonyushkin et al., 2005; Boysen et al., 2010; Durand and Storz, 2010; Argaman et al., 2012; Wright et al., 2013). In addition, both RyhB and FnrS have post-transcriptional regulatory targets in the iscR-iscS-iscU-iscA operon (Desnoyers et al., 2009; Wright et al., 2013). Our observation of both RyhB and FnrS regulating RseA is consistent with previously reported overlapping targets for RyhB and FnrS. RyhB and RseA are highly conserved in Gram-negative bacteria. It is possible that RyhB homologues or other small RNAs in these bacterial species regulate the posttranscriptional synthesis of RseA homologues.

For reasons that are not clear, there may be an increased requirement for RseA synthesis when iron, or oxygen, limitation occurs simultaneously with envelope stress. In our studies, we observed an increase in RseA-FLAG protein levels under iron-limiting conditions, implicating iron starvation in the post-transcriptional expression of the $\mathrm{RseA}_{\mathrm{P} 3}$ transcript. In the $\mathrm{cml}$ genetic background, RseA-FLAG protein levels decrease in the absence of RyhB (Figure 4D, lanes 3 vs 4). This supports our over-expression studies and implicate $\mathrm{RyhB}$ in the post-transcriptional stimulation of the $\mathrm{RseA}_{\mathrm{P} 3}$ expression. However, it is puzzling that the $r y h B$ mutant did not prevent an increase in RseA levels under iron-limiting conditions (Figure 4D, Lanes $1 / 2$ vs Lanes $5 / 6$ ). It is possible that the change in RseA protein levels is transient in nature. Further investigated is needed to fully ascertain the physiological link between iron limitation, RyhB, and RseA expression. However, it is clear that both iron limitation and chromosomal RyhB levels affect post-transcriptional expression of the $\mathrm{Rse}_{\mathrm{P} 3}$ transcript. This also further suggests that excess $\sigma^{\mathrm{E}}$ activity may be especially deleterious to the cell under iron limitation. There have been some studies executed in E. coli and Vibrio sp. that support a link between envelope stress and iron limitation. Under ironlimiting conditions, suboptimal secretion of the siderophore enterobacterin results in the induction of the Cpx-dependent
ESR (Guest et al., 2019). The Cpx-dependent ESR links iron sensing and adaptation in Vibrio cholerae (Acosta et al., 2015). The treatment of Vibrio vulnificus with the broad-spectrum antibiotic tropodithietic acid (TDA) simultaneously induced the expression of genes involved in cell envelope biogenesis, oxidative stress, and iron limitation (Dittman et al., 2019). Treatment of $V$. cholerae with polymyxin $\mathrm{B}$ results in induction of the $\sigma^{\mathrm{E}}$-dependent stress response and iron metabolism changes (Sikora et al., 2009). From studies in these systems, there appears to be a link between the iron metabolism and envelope stress. The precise mechanisms linking the iron metabolism and envelope stress are the subject of ongoing investigations in our lab.

\section{DATA AVAILABILITY STATEMENT}

The raw data supporting the conclusion of this article will be made available by the authors, without undue reservation.

\section{AUTHOR CONTRIBUTIONS}

LL, JA, and JN executed experiments associated with data in the article and also contributed to the writing and editing of the article. KT created the hypotheses driving the experiments in the study, designed the experiments associated with the data in the article, and contributed to the writing and editing of the article.

\section{FUNDING}

This work was supported by a grant (SC2GM105419) from the National Institute of General Medical Sciences (NIGMS) of the National Institutes of Health (United States), Howard University College of Medicine Bridge Fund and Pilot Study Award, Howard University Medical Alumni Association Basic Science Chair Award, and the Small Equipment and Research Resource Award from the Howard University Office of the Provost to KT. In addition, this work was also supported by a grant (1011634) from the National Institute of Food and Agriculture (NIFA) of the United States Department of Agriculture (USDA) to LL.

\section{ACKNOWLEDGMENTS}

We would like to thank members of the Thompson Lab for their comments and critique of this article. We would also like to thank Gisela Storz for generously donating plasmids pBR-fnrS-I, pBR-fnrS-II, and pBR-fnrS-III for this study. 


\section{REFERENCES}

Acosta, N., Pukatzki, S., and Raivio, T. L. (2015). The Vibrio cholerae Cpx Envelope Stress Response Senses and Mediates Adaptation to Low Iron. J. Bacteriol. 197, 262-276. doi:10.1128/jb.01957-14

Ades, S. E., Connolly, L. E., Alba, B. M., and Gross, C. A. (1999). The Escherichia coli Sigma E-Dependent Extracytoplasmic Stress Response Is Controlled by the Regulated Proteolysis of an Anti-Sigma Factor. Genes Develop. 13, 2449-2461. doi:10.1101/gad.13.18.2449

Afonyushkin, T., Vecerek, B., Moll, I., Blasi, U., and Kaberdin, V. R. (2005). Both RNase E and RNase III Control the Stability of sodB mRNA upon Translational Inhibition by the Small Regulatory RNA RyhB. Nucleic Acids Res. 33, 1678-1689. doi:10.1093/nar/gki313

Aiba, H., Adhya, S., and De Crombrugghe, B. (1981). Evidence for Two Functional Gal Promoters in Intact Escherichia coli Cells. J. Biol. Chem. 256, 11905-11910. doi:10.1016/s0021-9258(19)68491-7

Alba, B. M., Leeds, J. A., Onufryk, C., Lu, C. Z., and Gross, C. A. (2002). DegS and YaeL Participate Sequentially in the Cleavage of RseA to Activate the Sigma E-Dependent Extracytoplasmic Stress Response. Genes Dev. 16, 2156-2168. doi:10.1101/gad.1008902

Argaman, L., Elgrably-Weiss, M., Hershko, T., Vogel, J., and Altuvia, S. (2012). RelA Protein Stimulates the Activity of RyhB Small RNA by Acting on RNABinding Protein Hfq. Proc. Natl. Acad. Sci. 109, 4621-4626. doi:10.1073/ pnas.1113113109

Balbontín, R., Fiorini, F., Figueroa-Bossi, N., Casadesús, J., and Bossi, L. (2010). Recognition of Heptameric Seed Sequence Underlies Multi-Target Regulation by RybB Small RNA in Salmonella enterica. Mol. Microbiol. 78, 380-394. doi:10.1111/j.1365-2958.2010.07342.x

Boysen, A., Møller-Jensen, J., Kallipolitis, B., Valentin-Hansen, P., and Overgaard, M. (2010). Translational Regulation of Gene Expression by an Anaerobically Induced Small Non-Coding RNA in Escherichia coli. J. Biol. Chem. 285, 10690-10702. doi:10.1074/jbc.m109.089755

Campbell, E. A., Tupy, J. L., Gruber, T. M., Wang, S., Sharp, M. M., Gross, C. A., et al. (2003). Crystal Structure of Escherichia coli $\sigma \mathrm{E}$ with the Cytoplasmic Domain of its Anti- $\sigma$ RseA. Mol. Cel 11, 1067-1078. doi:10.1016/s1097-2765(03)00148-5

Chen, J., Morita, T., and Gottesman, S. (2019). Regulation of Transcription Termination of Small RNAs and by Small RNAs: Molecular Mechanisms and Biological Functions. Front Cel Infect Microbiol 9, 201. doi:10.3389/ fcimb.2019.00201

Chung, C. T., Niemela, S. L., and Miller, R. H. (1989). One-step Preparation of Competent Escherichia coli: Transformation and Storage of Bacterial Cells in the Same Solution. Proc. Natl. Acad. Sci. 86, 2172-2175. doi:10.1073/ pnas.86.7.2172

Costanzo, A., and Ades, S. E. (2006). Growth Phase-Dependent Regulation of the Extracytoplasmic Stress Factor, $\sigma$ E , by Guanosine $3^{\prime}, 5^{\prime}$-Bispyrophosphate (ppGpp). J. Bacteriol. 188, 4627-4634. doi:10.1128/jb.01981-05

Costanzo, A., Nicoloff, H., Barchinger, S. E., Banta, A. B., Gourse, R. L., and Ades, S. E. (2008). ppGpp and DksA Likely Regulate the Activity of the Extracytoplasmic Stress Factor $\sigma$ EinEscherichia Coliby Both Direct and Indirect Mechanisms. Mol. Microbiol. 67, 619-632. doi:10.1111/j.13652958.2007.06072.x

Dartigalongue, C., Missiakas, D., and Raina, S. (2001). Characterization of the Escherichia coliçE Regulon. J. Biol. Chem. 276, 20866-20875. doi:10.1074/ jbc.m100464200

De Las Penans, A., Connolly, L., and Gross, C. A. (1997). The sE-Mediated Response to Extracytoplasmic Stress in Escherichia coli Is Transduced by RseA and RseB, Two Negative Regulators of sE. Mol. Microbiol. 24, 373-385.

Desnoyers, G., and Masse, E. (2012). Noncanonical Repression of Translation Initiation through Small RNA Recruitment of the RNA Chaperone Hfq. Genes Develop. 26, 726-739. doi:10.1101/gad.182493.111

Desnoyers, G., Morissette, A., Prévost, K., and Massé, E. (2009). Small RNAInduced Differential Degradation of the Polycistronic mRNA iscRSUA. EMBO J. 28, 1551-1561. doi:10.1038/emboj.2009.116

Dittmann, K. K., Porsby, C. H., Goncalves, P., Mateiu, R. V., Sonnenschein, E. C., Bentzon-Tilia, M., et al. (2019). Tropodithietic Acid Induces Oxidative Stress Response, Cell Envelope Biogenesis and Iron Uptake in Vibrio Vulnificus. Environ. Microbiol. Rep. 11, 581-588. doi:10.1111/1758-2229.12771
Douchin, V., Bohn, C., and Bouloc, P. (2006). Down-Regulation of Porins by a Small RNA Bypasses the Essentiality of the Regulated Intramembrane Proteolysis Protease RseP in Escherichia coli. J. Biol. Chem. 281, 12253-12259. doi:10.1074/jbc.m600819200

Durand, S., and Storz, G. (2010). Reprogramming of Anaerobic Metabolism by the FnrS Small RNA. Mol. Microbiol. 75, 1215-1231. doi:10.1111/j.13652958.2010.07044.x

Erickson, J. W., Vaughn, V., Walter, W. A., Neidhardt, F. C., and Gross, C. A. (1987). Regulation of the Promoters and Transcripts of rpoH, the Escherichia coli Heat Shock Regulatory Gene. Genes Develop. 1, 419-432. doi:10.1101/ gad.1.5.419

Ezemaduka, A. N., Yu, J., Shi, X., Zhang, K., Yin, C.-C., Fu, X., et al. (2014). A Small Heat Shock Protein Enables Escherichia coli to Grow at a Lethal Temperature of 50 C Conceivably by Maintaining Cell Envelope Integrity. J. Bacteriol. 196, 2004-2011. doi:10.1128/jb.01473-14

Flynn, J. M., Levchenko, I., Sauer, R. T., and Baker, T. A. (2004). Modulating Substrate Choice: The SspB Adaptor Delivers a Regulator of the Extracytoplasmic-Stress Response to the AAA+ Protease ClpXP for Degradation. Genes Develop. 18, 2292-2301. doi:10.1101/gad.1240104

Guest, R. L., Court, E. A., Waldon, J. L., Schock, K. A., and Raivio, T. L. (2019). Impaired Efflux of the Siderophore Enterobactin Induces Envelope Stress in Escherichia coli. Front. Microbiol. 10, 2776. doi:10.3389/ fmicb.2019.02776

Johansen, J., Rasmussen, A. A., Overgaard, M., and Valentin-Hansen, P. (2006). Conserved Small Non-Coding RNAs that Belong to the $\sigma \mathrm{E}$ Regulon: Role in Down-Regulation of Outer Membrane Proteins. J. Mol. Biol. 364, 1-8. doi:10.1016/j.jmb.2006.09.004

Kabir, M. S., Yamashita, D., Koyama, S., Oshima, T., Kurokawa, K., Maeda, M., et al. (2005). Cell Lysis Directed by $\sigma$ E in Early Stationary Phase and Effect of Induction of the rpoE Gene on Global Gene Expression in Escherichia coli. Microbiology 151, 2721-2735. doi:10.1099/mic.0.28004-0

Kanehara, K., Ito, K., and Akiyama, Y. (2002). YaeL (EcfE) Activates the Sigma E Pathway of Stress Response through a Site-2 Cleavage of Anti-Sigma E, RseA. Genes Dev. 16, 2147-2155. doi:10.1101/gad.1002302

Klein, G., Lindner, B., Brade, H., and Raina, S. (2011). Molecular Basis of Lipopolysaccharide Heterogeneity in Escherichia coli. J. Biol. Chem. 286, 42787-42807. doi:10.1074/jbc.m111.291799

Klein, G., and Raina, S. (2017). Small Regulatory Bacterial RNAs Regulating the Envelope Stress Response. Biochem. Soc. Trans. 45, 417-425. doi:10.1042/ bst20160367

Klein, G., Stupak, A., Biernacka, D., Wojtkiewicz, P., Lindner, B., and Raina, S. (2016). Multiple Transcriptional Factors Regulate Transcription of the rpoE Gene in Escherichia coli under Different Growth Conditions and when the Lipopolysaccharide Biosynthesis Is Defective. J. Biol. Chem. 291, 22999-23019. doi:10.1074/jbc.m116.748954

Mandin, P., and Gottesman, S. (2009). A Genetic Approach for Finding Small RNAs Regulators of Genes of Interest Identifies RybC as Regulating the DpiA/ DpiB Two-Component System. Mol. Microbiol. 72, 551-565. doi:10.1111/ j.1365-2958.2009.06665.x

Masse, E., Escorcia, F. E., and Gottesman, S. (2003). Coupled Degradation of a Small Regulatory RNA and its mRNA Targets in Escherichia coli. Genes Develop. 17, 2374-2383. doi:10.1101/gad.1127103

Masse, E., and Gottesman, S. (2002). A Small RNA Regulates the Expression of Genes Involved in Iron Metabolism in Escherichia coli. Proc. Natl. Acad. Sci. 99, 4620-4625. doi:10.1073/pnas.032066599

Mecsas, J., Rouviere, P. E., Erickson, J. W., Donohue, T. J., and Gross, C. A. (1993). The Activity of Sigma E, an Escherichia coli Heat-Inducible Sigma-Factor, Is Modulated by Expression of Outer Membrane Proteins. Genes Dev. 7, 2618-2628. doi:10.1101/gad.7.12b.2618

Melamed, S., Peer, A., Faigenbaum-Romm, R., Gatt, Y. E., Reiss, N., Bar, A., et al. (2016). Global Mapping of Small RNA-Target Interactions in Bacteria. Mol. Cel 63, 884-897. doi:10.1016/j.molcel.2016.07.026

Miller, J. H. (1992). A Short Course in Bacterial Genetics. Plainview, N. Y.: Cold Spring Harbor Laboratory Press.

Missiakas, D., Mayer, M. P., Lemaire, M., Georgopoulos, C., and Raina, S. (1997). Modulation of the Escherichia coli $\sigma \mathrm{E}$ (RpoE) Heat-Shock Transcription-Factor Activity by the RseA, RseB and RseC Proteins. Mol. Microbiol. 24, 355-371. doi:10.1046/j.1365-2958.1997.3601713.x 
Nitta, T., Nagamitsu, H., Murata, M., Izu, H., and Yamada, M. (2000). Function of the $\varsigma$ E Regulon in Dead-Cell Lysis in Stationary-Phase Escherichia coli. J. Bacteriol. 182, 5231-5237. doi:10.1128/jb.182.18.5231-5237.2000

Prévost, K., Salvail, H., Desnoyers, G., Jacques, J.-F., Phaneuf, É., and Massé, E. (2007). The Small RNA RyhB Activates the Translation of shiA mRNA Encoding a Permease of Shikimate, a Compound Involved in Siderophore Synthesis. Mol. Microbiol. 64, 1260-1273. doi:10.1111/j.1365-2958.2007.05733.x

Ravio, T. L., Popkin, D. L., and Silhavy, T. J. (1999). The Cpx Envelope Stress Response Is Controlled by Amplification and Feedback Inhibition. J. Bacteriol. 18, 5263-5272.

Ravio, T. L. (1999). The sE and Cpx Regulatory Pathways: Overlapping but Distinct Envelope Stress Responses. Curr. Opin. Microbiol. 2, 159-165.

Rhodius, V. A., Suh, W. C., Nonaka, G., West, J., and Gross, C. A. (2006). Conserved and Variable Functions of the SigmaE Stress Response in Related Genomes. Plos Biol. 4, e2. doi:10.1371/journal.pbio.0040002

Semsey, S., Andersson, A. M. C., Krishna, S., Jensen, M. H., Massé, E., and Sneppen, K. (2006). Genetic Regulation of Fluxes: Iron Homeostasis of Escherichia coli. Nucleic Acids Res. 34, 4960-4967. doi:10.1093/nar/gkl627

Sikora, A. E., Beyhan, S., Bagdasarian, M., Yildiz, F. H., and Sandkvist, M. (2009). Cell Envelope Perturbation Induces Oxidative Stress and Changes in Iron Homeostasis in Vibrio cholerae. J. Bacteriol. 191, 5398-5408. doi:10.1128/ jb.00092-09

Thompson, K. M., Rhodius, V. A., and Gottesman, S. (2007). $\sigma$ E Regulates and Is Regulated by a Small RNA in Escherichia coli. J. Bacteriol. 189, 4243-4256. doi:10.1128/jb.00020-07

Udekwu, K. I., and Wagner, E. G. (2007). Sigma E Controls Biogenesis of the Antisense RNA MicA. Nucleic Acids Res. 35, 1279-1288. doi:10.1093/nar/ gkl1154

Vogt, S. L., Evans, A. D., Guest, R. L., and Raivio, T. L. (2014). The Cpx Envelope Stress Response Regulates and Is Regulated by Small Noncoding RNAs. J. Bacteriol. 196, 4229-4238. doi:10.1128/jb.02138-14
Walsh, N. P., Alba, B. M., Bose, B., Gross, C. A., and Sauer, R. T. (2003). OMP Peptide Signals Initiate the Envelope-Stress Response by Activating DegS Protease via Relief of Inhibition Mediated by its PDZ Domain. Cell 113, 61-71. doi:10.1016/s0092-8674(03)00203-4

Wright, P. R., Richter, A. S., Papenfort, K., Mann, M., Vogel, J., Hess, W. R., et al. (2013). Comparative Genomics Boosts Target Prediction for Bacterial Small RNAs. Proc. Natl. Acad. Sci. 110, E3487-E3496. doi:10.1073/pnas.1303248110

Yakhnin, H., Aichele, R., Ades, S. E., Romeo, T., and Babitzke, P. (2017). Circuitry Linking the Global Csr- and $\sigma E-D e p e n d e n t$ Cell Envelope Stress Response Systems. J. Bacteriol. 199, e00484-00417. doi:10.1128/JB.00484-17

Zhou, Y., and Gottesman, S. (1998). Regulation of Proteolysis of the StationaryPhase Sigma Factor RpoS. J. Bacteriol. 180, 1154-1158. doi:10.1128/ jb.180.5.1154-1158.1998

Conflict of Interest: The authors declare that the research was conducted in the absence of any commercial or financial relationships that could be construed as a potential conflict of interest.

Publisher's Note: All claims expressed in this article are solely those of the authors and do not necessarily represent those of their affiliated organizations, or those of the publisher, the editors, and the reviewers. Any product that may be evaluated in this article, or claim that may be made by its manufacturer, is not guaranteed or endorsed by the publisher.

Copyright (c) 2021 London, Aubee, Nurse and Thompson. This is an open-access article distributed under the terms of the Creative Commons Attribution License (CC $B Y)$. The use, distribution or reproduction in other forums is permitted, provided the original author(s) and the copyright owner(s) are credited and that the original publication in this journal is cited, in accordance with accepted academic practice. No use, distribution or reproduction is permitted which does not comply with these terms. 